\title{
INVESTIGATING THE EFFECT OF DIFFERENT ANIMAL VENOMS ON BREAST CANCER CELL LINES (MCF-7): IN VITRO STUDY
}

By

\author{
ABIR A. EL-FIKY ${ }^{1^{*}}$, HADY S. SHAHIN ${ }^{2^{*}}$, ALY F. MOHAMED ${ }^{1}$, \\ and SALMA M. EL-RAYES ${ }^{2 *}$ \\ VACSERA, Dokki, Giza ${ }^{1}$ and Faculty of Biotechnology, October University for Modern \\ Sciences and Arts (MSA), Egypt ${ }^{2}$ (Correspondence: *elfikyabir@gmail.com; \\ **alma.mohamed28@msa.edu.eg)
}

\begin{abstract}
Traditional treatments of cancer include surgery, chemotherapy, radiotherapy, hormone therapy, and combination therapy which affect both cancer and normal cells. The present study investigated anticancer venom potentials of Montivipera xanthina and Leiurus quinquestriatus compared to the synthetic anti-estrogen drug $\left(\right.$ Tamoxifen $\left.^{\circledR}\right)$ on MCF-7 breast cancer cell line. Cytotoxicity of venoms was evaluated using MTT assay. Cell cycle arrest was done using propidium iodide DNA stained by Flow Cytometry. Apoptosis was determined using annexin V-FITC by Flow Cytometry. Gene expression analysis was done for Caspase3, HER2, ER, and Survivin using qRT-PCR 24hrs post treatment and histological examination. L. quinquestriatus \& M. xanthina venoms and tamoxifen had $\mathrm{IC}_{50}$ at 2.5, $34.4 \& 27.8 \mu \mathrm{g} / \mathrm{mL}$ with $M C F-7$ cell line respectively. Cell cycle was ceased at G1/S phase of $L$. quinquestriatus and $M$. xanthina compared to tamoxifen. In gene expression analysis, venoms and tamoxifen exhibited apoptotic effect against MCF-7 cell lines by elevated expression of Caspase $3 \&$ depletion of HER2, ER, and Survivin. Histological examination showed apoptotic and slightly necrotic features in both venoms. Tamoxifen induced a number of apoptotic bodies and colonies of necrotic cells
\end{abstract}

Keywords: Venom, Montivipera xanthina, Leiurus quinquestriatus, MCF-7 breast cancer cell line, cytotoxicity, apoptosis, Caspase-3, HER2, ER, Survivin.

\section{Introduction}

Cancer is a group of diseases causing uncontrolled growth of abnormal cells characterized by insufficient apoptosis and metastatic capabilities (American Cancer Society, 2017). Breast cancer is one of the commonest diseases in women (lobules, ducts \& connective tissues) and the second cause of their mortality (Bajrami et al, 2018). Globally, breast cancer was estimated with 1.67 million new cancer cases; $11 \%$ of all diagnosed cancers (Feraly et al, 2015). Sporadic breast cancer (somatic genes related-mutations combined with environmental factors) and/ or hereditary cancer (Kenemans et al, 2004). The naturally extractions were attractive alternative drugs. Bioactive molecules in venoms extracts of several animals such as, snakes, scorpions, spiders, bees, and frogs stimulated new pharmacological anticancer agents (Abdel-Aziz et al, 2017). The venoms consisted of mixtures of proteins, nonproteins, peptides, enzymes and toxins intended to target vital biological and physiological actions (Gomes et al, 2010). Bioac tivity and biodiversity of venoms components were characterized among highest specific anticancer agents safe to normal cells and tissues (Omran, 2003). Snake and scorpion venoms proved effective anti-cancer therapy (Chaisakul et al, 2016). Snake venom, mixture of bioactive peptides, proteins, enzymes and toxins include cytotoxins, cardiotoxins \& neurotoxins, exhibited cytotoxic activities (Aart and Khusro, 2013). Venom targets cellular metabolism alterations rendering it potential anticancer \& anti-oxidant to block some specific ion channels, inhibited angiogenesis, obliterated metastasis, \& activated intracellular pathways causing apoptosis (Ebrahim et al, 2015). Snake venom antitumor activity: phospholipase- $\mathrm{A}_{2}$ from Bothrops jaracaussu, nigexine from Naja nigricollis, L-amino acid oxidase from Vipera berus, contortrostatin from Agkistrodon contortrix and viperistatin from Vipera xanthina (Bonfim et al, 2009). Consequences of scorpion stings on affected victims, including man, were known from ancient times, peptides employed action basis on affecting specific 
ion channels function $\left(\mathrm{Na}^{+}, \mathrm{K}^{+}, \mathrm{Ca}^{++} \& \mathrm{Cl}^{-}\right)$ active alteration of abnormal expression binding cancer process included cell adhesion, invasive proliferation, migration and apoptosis (Ortiz and Possani, 2018). In vitro \& in vivo studies proved anticancer potential bioactive components of scorpion venom: bengalin from Heterometrus bengalensis, margatoxin from Centruroides margaritatus, neopladine $1 \& 2$ from Tityus discrepans and chlorotoxin \& charybdotoxin from Leiurus quinquestriatus (Ding et al, 2014). HER-2, Estrogen receptor, Caspase-3, and Survivin are proteins with a pivotal role in metastasis and apoptosis. Human epidermal growth factor receptor-2 (HER2) is a member of HER receptors family with a tyrosine kinase activity. HER2 has marked role in growth, survival, differentiation \& proliferation of cells by many signal transduction pathways (Iqbal, 2014). Estrogen receptors are proteins actvated by estrogen hormone, proteins control gene expression \& cells proliferation (Groos and Yee, 2002). Capasase-3, a thiol protease of aspartate cysteine protease family is one of executioner caspases, \& a key mediator of apoptotic pathways (Devarajan et al, 2002; Donovan et al, 2003). Survivin, silenced in normal tissue but, overexpressed in malignant tissues consists of an inhibitor of apoptosis proteins with overexpression most cancer cells contributed to resistance to apoptotic stimuli and chemotherapies, thus contributed to on-going survival. It inhibits apoptosis promoting cell division, and enhance. Cross-correlation between genes was a significant determined drug-induced anti-proliferative, anti-antigenic, anti-metastatic, and apoptotic activities (Lv et al, 2010).

This study aimed to evaluate the anticancer potential of animal venoms of Leiurus quinquestriatus and Montivipera xanthina compared to synthetic hormonal anticancer drug $\left(\right.$ Tamoxifen $^{\circledR}$ ) on MCF-7 cells (human breast adenocarcinoma cell line).

\section{Materials and Methods}

Cell culture and MTT staining, penicillinstreptomycin, 25\% trypsin-EDTA, and pro- pidium iodide DNA staining were purchased (Sigma Chemicals Co, USA). Cell culture grade dimethyl-sulfoxide (DMSO), medium RPMI1640, human breast cancer (MCF-7) cell line was kindly supplied from $\mathrm{R} \& \mathrm{D}$ Sector, The International Center for Advanced Research. Venoms of $M$. xanthina and $L$. quinquestriatus and Tamoxifen ${ }^{\circledR}$ drug were purchased (VACSERA, Egypt). Annexin VFITC was from Bio-Vision Research Products, USA \& iScript ${ }^{\mathrm{TM}}$ One-Step Real TimePCR Kit with $\mathrm{SYBR}^{\circledR}$ Green was from BioRad Laboratories, USA. Venoms were prepared by diluting $1 \mathrm{mg}$ of each in $1 \mathrm{~mL}$ phosphate buffer saline (PBS). Drug was prepared by dissolving 10mg of Tamoxifen tablet in 5mL DMSO solution. All materials were serially diluted in RPMI-1641 media to need concentrations (Gajski et al, 2014).

Maintenance of cell line and culture conditions: MCF-7 (Human breast adenocarcinoma cell line) was provided by VACSERA. Cells were cultured in RPMI medium in the T-75 flasks (Griener, Germany) supplemented with $10 \%$ fetal bovine serum. Cultures were kept at $37^{\circ} \mathrm{C}, \& 95 \%$ humidity with $5 \%$ $\mathrm{CO}_{2}$. Monolayer cells were trypsinized once reached $80 \%$ confluency (Masters, 2000).

Cell counting: Accurate cell number in suspension was calculated using haemocytometer (Soliman et al, 2013). Double fold dilution of the original cell suspension was prepared by adding $0.5 \mathrm{~mL}$ of undiluted cell to $0.5 \mathrm{~mL}$ of $0.4 \%$ trypan blue dye, mixed well and immediately aspirated onto haemocytometer counting chambers.

Cytotoxicity using MTT reagent assay: Cells were put in the 96-well tissue culture plate with $100 \mu \mathrm{L}$ of RPMI medium. $200 \mu \mathrm{L}$ of the materials and diluted serially twice. Plates were then incubated with each venom concentrations for $24 \mathrm{hr}$ at $37^{\circ} \mathrm{C}$. For MTT assay, the 96-well plate was washed by PBS $\& 50 \mu \mathrm{L}$ MTT, added into each well, incubated for $3 \mathrm{hr}$ at $37^{\circ} \mathrm{C}$. $50 \mu \mathrm{L}$ of isopropanol was added and then incubated for $5 \mathrm{~min}$ at $37^{\circ} \mathrm{C}$. Plates were read by ELISA reader at wavelength $570 \mathrm{~nm}$ and absorbance correlat- 
led with cell number (Houghton et al, 2007). Cytotoxic effects of venoms on the $M C F-7$ cell lines were expressed as $\mathrm{IC}_{50}$ value (drug reduced absorbance of treated cells by $50 \%$ ). Inhibitory $\mathrm{IC}_{50}$ of compounds was assessed by Masterplex software (2010).

Inverted phase contrast microscopy: Morphological changes of treated MCF-7 cells with each venom and tamoxifen were examined $24 \mathrm{hr}$ post treatment (Soliman et al, 2013).

Cell cycle analysis using propidium iodide DNA staining by flow cytometry (Riccardi and Nicoletti, 2006): Cells were harvested in an appropriate manner, washed with PBS, and fixed in cold $70 \%$ ethanol and vortexing, pellet was added drop wise. Cells were fixed for $30 \mathrm{~min}$ at $4^{\circ} \mathrm{C}$ and minimized clumping. After fixation, cells were washed in PBS \& spun at $850 \mathrm{~g}$. Supernatant was discarded and cells were treated with ribonuclease I (100mg/ml stock solution). $50 \mu 1$ of $100 \mu \mathrm{g} / \mathrm{ml}$ sock of RNase were added to ensure DNA was stained. Propidium iodide $(200 \mu \mathrm{l})$ was added $(50 \mu \mathrm{g} / \mathrm{ml}$ stock solution).

Apoptotic detection using Annexin VFITC assay by flow Cytometry: $1-5 \times 10^{5}$ cells were collected by centrifugation, suspended in $500 \mu 1$ of $1 \mathrm{X}$ binding buffer. $5 \mu 1$ of Annexin V-FITC and $5 \mu 1$ of propidium io- dide (PI 50mg/ml) were added. Cells were left at room temperature for $5 \mathrm{~min}$ in dark. Annexin V-FITC binding was analyzed by flow cytometry $(E x=488 \mathrm{~nm} ; E m=530 \mathrm{~nm})$ using FITC signal detector and PI staining by phycoerythrin emission signal detector. For cells adherent, they were gently trypsinized and washed once with serum-containing media before incubation with Annexin V-FITC.

Gene expression analysis after treatment with venoms and tamoxifen: Expression of regulatory and apoptotic genes (Her2, ER, Casp-3, \& Survivin) were examined by realtime PCR in $M C F-7$ cell lines. Primer sequences of oligonucleotides were used (Tab. 1). Total RNA was extracted from treated and untreated $M C F-7$ cells $24 \mathrm{hr}$ post treatment using iScript ${ }^{\mathrm{TM}}$ One-Step real-time PCR Kit with SYBR ${ }^{\circledR}$ Green (Bio-Rad Laboratories, USA) by real-time quantitativePCR of RNA templates. cDNA synthesis and PCR amplification were done simultaneously. Melting curve of PCR products was performed by StepOneTM Real Time Systems software V.2.2.2.

The relative quantification for the genes (HER2, ER, Casp-3, \& Survivin) was calculated using equation: $\mathrm{FLD}=\mathrm{e}^{\wedge}-[(\mathrm{TE}-\mathrm{HE})-$ $\mathrm{TC}-\mathrm{HC}]=\mathrm{e}^{\wedge}-\Delta \Delta \mathrm{CT}$

Table 1: Primer sequences for genes (Quality Endorsed Company)

\begin{tabular}{|c|}
\hline $\begin{array}{l}\text { HER2-F: 5'-ACAACCAAGTGAGGCAGGTC-3" } \\
\text { HER2-R: 5'-GTATTGTTCAGCGGGTCTCC-3" } \\
\text { ER-F 5'-TAC TGC ATC AGA TCC AAG GG-3" } \\
\text { ER-R 5'- ATC A.A T GGT GCA CTG GTT GG -3" }\end{array}$ \\
\hline $\begin{array}{l}\text { Casp-3-F 5'-TTC ATT ATTCAG GCC TGC CGA GG-3' } \\
\text { Casp-3-R 5'-TTC TGA CAG GCC ATG TCA TCC TCA-3' }\end{array}$ \\
\hline $\begin{array}{l}\text { Survivin-F: } 5^{\prime} \text {-GCA TGG GTG CCC CGA CGT TG-3" } \\
\text { Survivin-R: } 5^{\prime} \text {-GCT CCG GCC AGA GGC CTC AA-3" }\end{array}$ \\
\hline $\begin{array}{l}\text { B-actin-F 5'-GTGACATCCACACCCAGAGG-3' } \\
\text { B-actin-R 5'-ACAGGATGTCAAAACTGCCC-3' }\end{array}$ \\
\hline
\end{tabular}

Histologically: Detached and adhered cells were collected post treatment using trypsin. Pelleted cells were re-suspended in PBS and a part $(50 \mu \mathrm{L})$ was dispensed on glass slide, dried and fixed using methanol. Fixed slides were rehydrated in descending ethanol and washed in distilled water for $5 \mathrm{~min}$. Slides were immersed in filtered hematoxylin stain for $3 \mathrm{~min}$, rinsed in distilled water twice, immersed in filtered eosin stain for $5 \mathrm{sec}$, and washed with distilled water. Clean slides were immersed in xylene, mounted in Canada balsam, covered cover-slips and left to dry.

Statistical analysis: Data were processed (Snedecor and Cochran, 1982); where minimum, maximum, mean value, standard deviation, standard error, and range were presented. For significance $t$. test was used for difference between two means, 


\section{Results}

Table1: Inhibitory effect of M. xanthina, L. quinquestriatus venoms and Tamoxifen on MCF-7 cell line by MTT assay.

\begin{tabular}{|c|c|c|c|}
\hline \multirow{2}{*}{$\mathrm{IC}_{50}$} & Xanthina/MCF-7 & Tamoxifen $/ M C F-7$ & Leiurus $/ M C F-7$ \\
\cline { 2 - 4 } & 34.40 & 27.80 & 2.50 \\
\hline
\end{tabular}

Cytotoxicity of M. xanthine, L. quinquestriatus venoms and Tamoxifen were $2.5 \mu \mathrm{g}$ on MCF-7 cell line using MTT assay (Fig. $/ \mathrm{mL}, 27.8 \mu \mathrm{g} / \mathrm{mL} \& 34.4 \mu \mathrm{g} / \mathrm{mL}$ respectively

$1)$.

Table 2: Determination of cell cycle phases of $M C F-7$ cell line treated with animal venoms and Tamoxifen using Propidium iodide DNA staining by Flow Cytometry.

\begin{tabular}{|c|c|c|c|c|c|c|}
\hline & Sample (Conc. ug/ml) & \multicolumn{4}{|c|}{ Phases of cell cycle } \\
\hline & Sample code & $\% \mathrm{G} 0-\mathrm{G} 1$ & $\% \mathrm{~S}$ & $\% \mathrm{G} 2-\mathrm{M}$ & $\%$ Pre-G1 & Comment \\
\hline 1 & Tamox/MCF-7 & 43.11 & 20.97 & 2.87 & 33.05 & PreG1apoptosis\&Cell growth arrest@G1/S \\
\hline 2 & Leiu $/ M C F-7$ & 62.29 & 17.23 & 1.28 & 19.20 & PreG1apoptosis\&Cell growth arrest@G1/S \\
\hline 3 & Xan $/ M C F-7$ & 59.41 & 23.16 & 1.79 & 15.69 & PreG1apoptosis\&Cell growth arrest@G1/S \\
\hline 4 & Cont.MCF-7 & 72.33 & 15.31 & 9.41 & 2.95 & \\
\hline
\end{tabular}

Morphology showed cell rounded, condensed with cellular rupture and significant reduced treated cells number compared to control ( $\mathrm{p} \geq 0.05$ ). Treated $M C F-7$ cells with

venoms \& tamoxifen were significant timedependent increased cells in G0/ G1 population, followed by cells arrest in G1/S after 24hr. no apoptosis in control (Fig. 3-4).

Table3: Death of treated MCF-7 cells with animal venoms and tamoxifen drug in total, early \& late apoptosis and necrosis.

\begin{tabular}{|l|c|c|c|c|}
\hline \multicolumn{1}{|c|}{ Variants } & Apoptosis total & Apoptosis early & Apoptosis late & Necrosis \\
\hline Tamo/MCF-7 & 33.05 & 9.66 & 20.14 & 3.25 \\
\hline Leiu $/ M C F-7$ & 19.20 & 6.41 & 8.16 & 4.63 \\
\hline Xan $/ M C F-7$ & 15.69 & 5.46 & 7.88 & 2.35 \\
\hline Cont.MCF-7 & 2.95 & 1.38 & 0.52 & 1.05 \\
\hline
\end{tabular}

Venoms and Tamoxifen induced apoptosis apoptosis and necrosis by venoms and taon $M C F-7$ cell line, in total, early, \& late moxifen compared to control (Fig. 5).

Table4: Gene expression levels of HER2, ER, Survivin and Casp3 in treated and untreated MCF-7 cell line.

\begin{tabular}{|l|l|c|c|c|c|}
\hline Ser & Sample code & HER2 & ER & Survivin & Casp3 \\
\hline 1 & Tamoxifen/MCF7 & 0.064824 & 0.545211 & 0.648558 & 8.392726 \\
\hline 2 & Leiurus $/ M C F 7$ & 0.077763 & 0.476295 & 0.520668 & 6.612089 \\
\hline 3 & Xanthina/MCF7 & 0.080746 & 0.404457 & 0.450689 & 4.771106 \\
\hline 4 & cont.MCF7 & 1 & 1 & 1 & 1 \\
\hline
\end{tabular}

Gene expression levels of pro-apoptotic genes as Caspase 3 and anti-apoptotic genes as HER2, ER \& Survivin were examined in MCF-7 cell line post treatment with $\mathrm{IC}_{50}$ of venoms and tamoxifen compared to control. Venoms and tamoxifen induced the up regulation of pro-apoptotic gene Caspase 3 and down regulation of anti-apoptotic genes (HER2, ER \& Survivin) on breast cancer $M C F-7$ cell lines (Fig. 6).

Histologically treated $M C F-7$ cell line with venoms \& tamoxifen compared to untreated one were detected. Control showed regular tumour of cellular and nuclear pleomorphisms. Cells were regular, hyperchromatic and condensed nuclei. Cellular outline regular without any folding in cellular membrane. Some cells showed cellular and nuclear pleomorphism (Fig. 7). Treated $M C F-7$ cells with tamoxifen showed late apoptosis of multiple bodies and remnants of necrotic cells (Fig. 8). MCF-7 cells treated with Leiurus venom were shrunken with irregular nuclear \& cell membranes, membrane blebbing, peripheral condensation of chromatin and nucleolar segregation. Swollen necrotic cells with irregular membrane, necrotic cell debris and apoptotic bodies (Fig. 9). MCF-7 cells treated with Montivipera venom showed apoptosis as shrunken cells, nuclei irregular, cellular \& nuclear membranes, peripheral condensation of chromatin and nucleolar segregation (Fig. 10).

\section{Discussion}

Chaubey (2017) reported a significant advancement in cancer therapy possibility to 
synthesize peptides and proteins specific for oncoproteins. Chaisakul et al. (2016) found that the anticancer effects of venoms of animal species including snakes and scorpions and their biochemical derivatives proved to be potential therapeutic tools. Cytotoxicity of snake families and their potential induced anticancer activities in sarcoma, leukemia and carcinoma models. Venom from Viperdae family acts directly affected breast cancer cells (Gomes et al, 2010). Yalcin et al. (2014) reported that M. xanthina venom was used for different cancer cells types as anticancer agents. Ahluwalia and Shah (2014) found that by increasing concentration of snake venom, cytotoxicity increased and affected proliferation of breast cancer cells. Inhibitory concentration of Viperidae snake venoms of $M$. xanthina, Crotalus oreganus cerberus and Bothrops alternatus toward MCF-7 cells after $24 \mathrm{hr}$ incubation was at $4.2,17.5 \& 63.5 \mu \mathrm{g} / \mathrm{mL}$ respectively (Yalcin et al, 2014; Bradshaw et al, 2016). $\mathrm{IC}_{50}$ for Russell's viper venom was $35.5 \mu \mathrm{g} / \mathrm{mL}$ on leukemic cancer cells after $48 \mathrm{hr}$ post treatment (Gomes et al, 2015).

In the present study, $M C F-7$ cells treated with Montivipera venom for $24 \mathrm{hr}, \mathrm{IC}_{50}$ value was $34.4 \mu \mathrm{g} / \mathrm{mL}$. This agreed with Gomes et al. (2015) but disagreed with Yalcin et al. (2014) and Bradshaw et al. (2016). This might be due to difference in animal species and/or habits as venom source. Lethality of Leiurus venom $(17 \mathrm{mg})$ injected into normal man caused less than $50 \%$ survival chance, and reduced cell survival chance at higher concentrations and destruction of other cells by different mechanisms. Abdel-Aziz et al. (2017) reported that $\mathrm{IC}_{50}$ of Leiurus venom was $2.5 \mu \mathrm{g} / \mathrm{mL}$ on $M C F-7$ cell line after $48 \mathrm{hr}$ incubation. In the present study, the $\mathrm{IC}_{50}$ of Leiurus on MCF-7 cell line after $24 \mathrm{hr}$ incubation was $2.50 \mu \mathrm{g} / \mathrm{mL}$. But, MCF-7 cell line exposed to tamoxifen for $72 \mathrm{hr}, \mathrm{IC}_{50}$ was $23.9 \mu \mathrm{g} / \mathrm{mL}$ (Lord and Ashworth, 2010). In the present study, $\mathrm{IC}_{50}$ of $M C F-7$ treated with tamoxifen was $27.8 \mu \mathrm{g} / \mathrm{mL}$. Difference in both results was quite similar with slight variation due to artefacts and minor data anomalies. Scorpion venom has higher toxins than snake one (Omran, 2003). Venom of Leiurus was more toxic and potent than that of Montivipera and tamoxifen. Snake venoms reduced cell proliferation and induced morphological alterations related apoptosis: detachment of cells, rounding, chromatin condensation, cytoplasmic blebs and irregularly shaped (Ebrahim et al, 2014). Montivipera venom by inverted microscopy showed changes in MCF-7 cell line (Yalcin et al, 2014). Calderon et al. (2014) found that lectins isolated from Vipera venom affected proliferation of human cancer cell lines and alter cell adhesion inducing apoptosis. Also, scorpion venom inhibited growth and proliferation in cancer cell types (Aarti and Khusro, 2013). Leiurus venom caused morphological changes, exhibited apoptotic cells as, condensation and compartmentalization of nuclear and cytoplasmic materials (Omran, 2003). Chaisakul et al. (2016) isolated Chlorotoxin (CITx) from L. quinquestriatus venom conjugated with its synthetic compound (TM601) inhibited cancer development by attenuating $\mathrm{Cl}^{-}$conductance $\&$ angiogenesis and CTLx prevented aggressive metastatic breast cancer cells. Treatment of breast cancer with tamoxifen gave effective palliation but without eradication of cancer cells. It caused cytostasis in $M C F$ 7 cells by proliferation of cell line and morphologically tamoxifen analogue toremifene induced apoptosis (60\%) of MCF-7 cells (Wilson et al, 1995). Venoms and tamoxifen on $M C F-7$ cell line gave significant inhibitory effects, cellular proliferation and morphological changes related to cell death as condensed in size and a small round cell shape after $24 \mathrm{hr}$ incubation significantly reduced cell number. Reduction of cell proliferation might be due to lectins in venom of snake or CTLx or scorpion. Chaisakul et al. (2017) showed that cytotoxins of snake venom effected cancer cell proliferation, migration, invasion, neovascularization and apoptosis by arresting cell cycle in Pre-G1 population. 
Russell's viper venom arrested cell cycle in G1/S phase on leukemic U937 cancer cells $24 \mathrm{hr}$ post treatment (Gomes et al, 2015). Salmosin disintegrins from Korean snake inhibited angiogenesis without toxicity to normal blood vessels and induced cell cycle arrest led to apoptosis (Chaisakul et al, 2016). Obtustatin disintegrins from Vipera lebetina obtuse inhibited angiogenesis reduced tumour development and hindered growth (Rahman and Choudhary, 2016). Gomes et al. (2010) found that charybdotoxin (CTX) of L. quinquestriatus venom caused a slight depolarization in breast cancer cells, arrested cell cycle at early $\mathrm{G} 1$, late $\mathrm{G} 1, \& \mathrm{~S}$ phases and gathered cells in $\mathrm{S}$ phase by blocking $\mathrm{Ca}^{2+}$ activated $\mathrm{K}^{+}$channel. Blockage of specific ion channels impaired cancer growth \& metastasis and activated intracellular pathways to cell cycle arrest \& apoptosis (Chaubey, 2017). Tamoxifen inhibited proliferation of $M C F-7$ cells and reduced in S phase, accumulation in G1 early phase, concomitant depletion of G2/M phase by hindering cell cycle in early G1 phase (Osborne et al, 1983). In the present study, both venoms and tamoxifen induced G1/S cell cycle arrest on $M C F-7$ cells after $24 \mathrm{hr}$ incubation. Anti-proliferative activity inhibited cell growth in G1 /S causing apoptosis during Pre-G1 by targeting cancer cell proliferation, migration, invasion, neovascularization and apoptotic activity (Chaisakul et al, 2016). Cytotoxicity of snake v-nom targets cellular metabolism alterations and affected cancer cells; blocked some specific ion channels, inhibiting angiogenesis \& activating intracellular pathways causing apoptosis (Ebrahim et al, 2015). They potentially induced apoptosis by forming apoptotic body, increasing in subG1 population, fragmenting cells DNA and cleaving poly (ADP-ribose) polymerase (PARP) (Gomes et al, 2010). Activity of $\mathrm{Na}^{+}, \mathrm{K}^{+}$, $\mathrm{Ca}^{++} \& \mathrm{Cl}^{-}$ion channels altered abnormal expression binding to cancer processes involving cell volume and motility and cell proliferation with final death (Ding et al, 2014). Rahman and Choudhary (2016) reported that
Viperistatin from Vipera xanthina venom was characterized as KTS motif in the integrin active binding site loop to block $\alpha 1 \beta 1$ integrin. Anti-angiogenic cyclic KTS peptides blocked binding of $\alpha 1 \beta 1 \& \alpha 2 \beta 1$ integrins. Obtustatin from $V$. lebetina obtuse venom, activated inhibiting proliferation, \& alteration in cell adhesion by apoptosis induction (Calderon et al, 2014). Chaisakul et al. (2016) reported that active components of snake venom as PLA2 and lectin from Bothrops jararacussu potential affected cancer. PLA2 induced apoptosis in cancers: breast adenocarcinoma, leukemia $\mathrm{T}$ and Erlich ascetic tumour cell line. Omran (2003) reported that apoptosis included a cascade of cytoplasmic and nuclear events causing a series of morphological changes and eventually cell demise by various stimuli. Nevertheless, necrosis caused cell lysis and extensive damage surrounding tissues physically and/ or oxygen starvation. Rapid cytotoxicity effects of leiurus venom occurred within 30 min. causing lysis of plasmalemma and organelle membranes that led to rapid death of a great cell population. Effects of cell death in $T 47 D$ (breast cancer cell line) treated with Leiurus venom showed significant cell death in different concentrations (Omran, 2003). So, when chlorotoxin bind with $\mathrm{Cl}^{-}$channel in membrane protein, chlorotoxin interacted and killed the cancer cells by ion modulation. Also, chlorotoxin bind with MMP-2 caused reduction of expression of MMP- 2 and regression induction of aggressive metastatic breast cancer cells (King, 2011). But, tamoxifen and its analogues induced death of human breast cancer cells in both in vivo and in vitro studies. Tamoxifen and its metabolite 4-hydroxy caused morphological changes by cleavage of DNA inducing apoptosis on MCF-7 cells (Wilson et al, 1995). In the present study, $M C F-7$ cell line treated with venoms and tamoxifen showed cell death by using annexin V-FITC after $24 \mathrm{hr}$ treatment. Apoptosis of treated MCF-7 with tested materials detected in total, early, and late apoptosis and necrosis as well. This agreed with 
Shirazi et al. (2014) who found that MCF-7 cell lines treated with Cobra venom gave early and late apoptosis and necrosis. This agreed with Omran (2003) who found that Leiurus venom caused an early significant apoptosis rather than necrosis on cancer cells. Apoptosis mediated by toxicity caused cell damage such as swelling, rupture, and necrosis. Tamoxifen treated MCF-7 cell line did not develop apoptosis under same conditions (Wilson et al, 1995), but induced apoptosis on $M C F-7$ cells. Venoms altered gene expression and increased expression of proapoptotic proteins (Chaisakul et al, 2016). Snake toxins increased expression of proapoptotic proteins and induced apoptosis via ROS-in-dependent mitochondrial dysfunction pathway and caspase-dependant mechanism of Bax/Bcl-2 ratio (Ebrahim et al, 2015). Snake cytotoxins mediated apoptosis via cleaving poly (ADP-ribose) polymerase (PARP) (Gomes et al, 2010). LAAOs stimulated apoptotic activity by oxidative reaction mediated with released $\mathrm{H}_{2} \mathrm{O}_{2}$ led to trigger apoptosis (Gomes et al, 2010). Chaisakul et al. (2016) isolated LAAO from king cobra venom exhibited a specific anticancer activity on human breast adenocarcinoma cell line by extrinsic and intrinsic pathways enhanced of activities of caspase- 8 \& caspase- 9 induced cell apoptosis. Induction of cell-cycle arrest in breast cancer cell lines was done by caspase-dependent apoptosis by snake venoms. The expression of active Caspase-3 was increased in $M D A-M B-231$ and $M C F-7$ breast cancer cells treated with snake venom (Al-Sadoon et al, 2018). Scorpion venom induced anti-proliferative effect by arresting S-phase and apoptosis through Capase-3 activity, nitric oxide production, DNA fragmentation \& depolarization of mitochondrial membrane (Ahluwalia and Shah, 2014). Chaisakul et al. (2016) found that bengalin from Heterometrus bengalensis venom acted on leukemic cells by activating Caspase-3, Caspase-9 and cleavage of induced poly (ADP-ribose) polymerase (PARP) reduced cell proliferation causing apoptosis. Activat- ion of Caspase-3, Caspase-7, Caspase-8, and Caspase-9 occurred after breast cancer cells tamoxifen treatment (Moriai et al, 2008). Tamoxifen induced potential activity of Caspase-3 in ER-negative breast cancer cell mediated by cleavage of fluorogenic tetra peptide substrate and poly (ADP-ribose) polymerase (Mandlekar et al, 2000).

In the present study, gene expression levels of pro-apoptotic genes such as Caspase 3 on $M C F-7$ cell line post treatment with $\mathrm{IC}_{50}$ of venoms and tamoxifen occurred in treated MCF-7 with tested materials. The present study reported the up-regulation of Capsase3 gene in breast cancer cell lines treated with venoms and tamoxifen. Snake venom inhibited migration of HER2 positive breast cancer cells by interrupting signal from epidermal growth factor receptors, applied stronger cytotoxic effects than therapies targeting receptors only (Karem et al, 2017). Ma et al. (2017) found that ADAM proteins and matrix meta-lloproteinases from scorpion venom activated HER2 receptor targeted for breast cancer cells. Proteolytic enzymes: Jararhagin \& Jararhagin C from Bothrops jararaca act by cleavage of growth factors and corresponding receptor (HER2) causing degradation of extracellular matrix \& inheritance of growth signalling. Overexpression of HER2 was associated in tamoxifen resistance in human breast cancer cells due to sensitivity (Shou et al, 2004). There existed ER- $\alpha 36-E G F R / H E R 2$ positive regulatory loops in HER2-expressing breast cancer cells and disruption of these regulatory loops restored tamoxifen sensitivity in these cells. (Yin et al, 2015). The present study showed expression level of anti-apoptotic gene of HER2 in MCF-7 cell line post treatment with $\mathrm{IC}_{50}$ of venoms and tamoxifen. Downregulation of HER2 gene was detected post treatment. The present results and others proved down-regulation of HER2 gene in breast cancer cell lines treated with venoms. But, not in tamoxifen treated $M C F-7$ cell line that might be attributed to difference between HER2 expression level and its' ac- 
tion. Purified snake venoms showed cytotoxic activity against MCF-7 (ER+) \& $M D A-M B-231$ (ER-) cells in a dose dependent manner (Attarde and Pandit, 2017). Erdes et al. (2014) found that L. abdullah bayrami venom has an anti-proliferative effect on $M C F-7(\mathrm{ER}+)$ breast cancer cell and L. quinquestriatus venom has anticancer effect on MCF-7 cell line (Abdel-Aziz et al, 2017), venom exhibited broad range of anticancer activity on MDA-MB-231 (ER-) cell line (Al-Asmari et al, 2015). Tamoxifen had influence on cytoskeleton of two ER positive cell lines as the standard therapy with ER+ breast cancer. But, many patients developed resistance to tamoxifen and reflected to both ER+ \& ER- cell lines (RondonLagos et al, 2016). Down-regulation of antiapoptotic gene ER was post treatment. The present study and others reported downregulation of ER gene in breast cancer cell lines treated with venoms and tamoxifen but with higher probability of resistance to tamoxifen. One of the prominent genes in P53 pathway is Survivin (BIRC5). Clinically, EME1, RAD51, EXO1, BLM expressions correlated with BIRC5 (coding for Survivin) and of prognostic value. Actively, Survivin depletion triggers P53 activation \& sensitized cancer cells to of PARP inhibition (Véquaud et al, 2016). Inhibition of Stat3 decreased expression of Survivin in breast cancer cells. Scorpion venom decreased Stat 3 on breast cancer lines, thereby decreasing expression of anti-apoptotic gene (Gritsko et al, 2006; Al-Asmari et al, 2018). But, tamoxifen induced apoptosis was blocked by Caspases present in breast cancer cells. Up-regulation of anti-apoptotic Survivin gene induced inhibition of Caspase-3 \& Caspase-7. Down-regulation of Survivin stimulated tamoxifen induced apoptosis by introducing siRNA targeting Survivin gene in $M C F-7$ cells. siRNA targeted-Survivin transfection did not induce apoptosis without tamoxifen treatment but augmented by induced apoptosis. Survivin acts as a factor conferred resistance against tamoxifen-enhanced apopto- sis (Moriai et al, 2009). This study showed the gene expression level of anti-apoptotic gene of Survivin in $M C F-7$ cell line post treatment with $\mathrm{IC}_{50}$ of venoms and tamoxifen. Down-regulation of anti-apoptotic gene Survivin occurred post treatment. Expression of anti-apoptotic Survivin gene reduced breast cancer cell line by induction of P53 pathway and/or inhibition of Stat3 signalling protein mediated by venoms. But, tamoxifen negatively regulated between Survivn gene and wild type Caspase-3 gene. Lipps (1998) reported that certain fractions isolated from snake venoms gave direct cytolytic activity on tumor cells. Snake cytotoxins induced apoptosis by forming apoptotic bodies and fragmented DNA cells (Gomes et al, 2010).

Venom post treatment was tissue necrosis, displayed potent cytotoxic effect and apoptotic effect on human leukemic cells (Ahluwalia and Shah, 2014). Elapid venom cytotoxins caused membrane damage and necrosis by mediating direct action with phospholipids membranes to form pores (Chaisakul et al, 2016). Omran et al. (2003) found morphologic dyed cells of scorpion venom were fragmented, condensed with shrinkage and vacuoles between adherent cells. By nuclear DNA fragmentation, venom caused apoptosis of tumour cells. Odonotobuthus doriae venom not only caused apoptosis but also inhibited DNA synthesis in $M C F-7$ breast cancer cell line (Ahluwalia and Shah, 2014). Tamoxifen caused chromatin condensation, nuclear fragmentation \& apoptosis (Mandlekar et al, 2000).

\section{Conclusion}

$M C F-7$ cells treated with venoms and tamoxifen histologically showed apoptosis as shrunken cell, shrunken nuclei, irregular cellular nuclear membranes, apoptotic bodies, peripheral ch-romatin condensation, nucleoli segregation and signs of necrosis. Snake (Montivipera xanthina) and scorpion (Leiurus quinquestriatus) venoms have anticancer action on human breast cancer compared with tamoxifen ${ }^{\circledR}$. Anti-cancer was proved by venoms cytoxicity, cell cycle cytox- 
icity, cell cycle arrest and up- and downregulations of pro \& anti-apoptotic genes.

\section{Acknowledgments}

The authors express their sincere gratitude and indebtedness to Faculty of Biotechnology Authorities for support and encouragement. Thanks also extended to VACSERA Authorities.

\section{References}

Aarti, C, Khusro, A, 2013: Snake venom as anticancer agent-current perspective. Int. J. Pure App. Biosci. 1, 6:24-9.

Abdel-Aziz, SAA, Mohamed, AF, Zahkouk, S AM, Ali, RAM, 2017: Evolution of anticancer activity of some venomous animal toxins on human breast and colon cancer cell line and related antioxidant profiles. Int. J. Adv. Res. 5, 2: 2036-53.

Al-Asmari, KA, Islam, M, Al-Zahrani, M, A, 2015: In vitro analysis of the anticancer properties of scorpion venom in colorectal and breast cancer cell lines, Pncol. Lett. 11:1256-62.

Al-Asmari, KA, Riyasdeen, A, Islam, M, 2018: Scorpion venom causes upregulation of p53 and downregulation of Bcl- $\mathrm{x}_{\mathrm{L}}$ and BID protein expression by modulating signaling proteins Erk $^{1 / 2}$ and STAT3, and DNA damage in breast and colorectal cancer cell lines. Integr. Cancer Ther. 17, 2:271-81.

Al-Sadoon, K, Riyasdeen, A, Islam, M, 2018: Induction of apoptosis and growth arrest in human breast carcinoma cells by a snake (Walterinnesia aegyptia) venom combined with silica nanoparticles: crosstalk between $\mathrm{Bcl} 2$ and caspase 3. Cell Physiol. Biochem. 30, 3:653-65.

American Cancer Society, 2017: Cancer Facts \& Figures 2017, Atlanta: American Cancer Society.

Attarde, S, Pandit, S, (2017): Cytotoxic activity of NN-32 toxin from Indian Spectacled Cobra venom on human breast cancer cell line. Clin. Therap. 39, 8:e72-3.

Bajrami, I, Marlow, R, van de Ven, M, Brough, R, et al, 2018: E-Cadherin/ROS1 inhibitor synthetic lethality in breast cancer. Am. Assoc. Cancer Res. 8, 4:498-515

Bonfim, LV, de Carvalho, DD, Ponce-Soto, AL, Kassab, HB, Marangoni, S, 2009: Toxicity of phospholipase $A_{2}$ D49 (6-1 \& 6-2) and K49 (Bj-VII) from Bothrops jararacussu venom, Cell Biol.Toxicol. 5:23-32.

Bradshaw, JW, Saviola, JA, Fesler, E, Macke- ssy, PS, 2016: Evaluation of cytotoxic activities of snake venoms toward breast (MCF-7) and skin cancer (A-375) cell lines. Cytotechnology 68, 4:687-700.

Calderon, L, Sobrinho, CJ, Zaqueo, DK, De Moura, AA, Grabner, NA, et al, 2014: Antitumoral activity of snake venom proteins: new trends in cancer therapy, Hindawi Publishing Corporation: Bio-Med. Res. Inter. Article ID: 203639:19.

Chaisakul, J, Hodgson, WC, Kuruppu, S, Prasongsook, N, 2016: Effects of animal venoms and toxins on hallmarks of cancer. J. Cancer 7, 11:1571-8.

Chaubey, KM, 2017: Scorpion venom: Pharmacological analysis and its application, Euro. J.

Biol. Res. 7, 4:271-290.

Devarajan, E, Sahin, AA, Chen, SJ, Krishnamurthy, RR, Aggarwal, N, et al, 2002: Downregulation of caspase 3 in breast cancer: a possible mechanism for chemoresistance, Nature Publishing Group 21:8843851.

Ding, J, Chua, P, Bay, B, Gopalakrishnakone, P, 2014: Scorpion venoms as a potential source of novel cancer therapeutic compounds. Exp. Biol. Med. (Maywood). 239, 4:387-93.

Donovan, ON, Crown, J, Stunell, H, Hill, KD A, McDermott, E, et al, 2003: Caspase 3 in breast cancer. Clin. Cancer Res. 9:738-42.

Ebrahim, K, Shirazi, FH, Mirakabadi, AZ, Vatanpour, H, 2015: Cobra venom cytotoxins; apoptotic or necrotic agents? Toxicon 108:13440.

Ebrahim, K, Shirazi, HF, Vatanpour, H, Zare, A, Kobarfard, F, Rabiei, H, 2014: Anticancer activity of cobra venom polypeptide, cytotoxin-II, against human breast adenocarcinoma cell line (MCF-7) via the induction of apoptosis. J. Breast Cancer 17: 314-22.

Erdes, E, Dogan, T, Cosar, I, Danisman, T, Kunt, K, et al, 2014: Characterization of Leiurus abdullahbayrami (Scorpions: Buthidae) venom: Peptide profile, cytotoxicity and antimicrobial activity. J. Venom. Anim. Toxins including Trop. Dis. 20, 1:48-52.

Feraly, J, Soerjomataram, I, Dikshit, R, Eser, S, Mathers, C, et al, 2015: Cancer incidence and mortality worldwide: source, methods and major patterns in GLOBOCAN 2012, Inter. J. Cancer 136:359-86.

Gajski, G, Zovko, CT, Rak, S, Vrhovac, GV, 2014: Combined antitumor effects of bee venom and cisplatin on human cervical and laryngeal 
carcinoma cells and their drug resistant sublines, Toxicology 34:

Gomes, A, Bhattacharjee, P, Mishra, R, Biswas, KA, Dasgupta, CS, et al, 2010: Anticancer potential of animal venoms and toxins. Indian J. Exp. Biol. 48:93-103.

Gomes, A, Biswas, AK, Bhowmik, T, Saha, P P, Gomes, A, 2015: Russell's Viper venom purified toxin dcrt-II inhibits the cell proliferation \& induces G1 cell cycle arrest in human leukemic cancer cells. Translat. Med. 5, ISSN: 2161-1025

Gritsko, T, Williams, A, Turkson, J, Kaneko, S, Bowman, T, et al, 2006: Persistent activation of Stat3 signaling induces survivin gene expression and confers resistance to apoptosis in human breast cancer cells. Clin. Cancer Res.12:11-9.

Iqbal, N, 2014: Human epidermal growth factoe receptor 2 (HER2) in cancers: Overexpression and therapeutic implications. Mol. Biol. Inter. Article ID: 852748:.9.

Karem, N, Badr, DA, Mohamed. AF, 2017: In-vitro assessment of anticancer potential of lapatinab and bee venom against breast (MCF-7) and prostate (PC-3) cancer cell lines: In-vitro study. Inter. J. Sci. Res. (IJSR), Vol.6, ISSN. 6.

Kenemans, K, Verstraeten, AR, Verheijen, $M$ HR, 2004: Oncogenic pathways in hereditary and sporadic breast cancer. Maturitas 49, 1:3443.

King, GF, 2011: Venoms as a platform for human drugs: Translating toxins into therapeutics. Expert. Opin. Biol. Ther. 11:1469-84.

Lipps, VB, 1998: Novel snake venom proteins cytolytic to cancer cells in vitro and in vivo systems. J. Venom. Anim. Toxins 5, 2:On-line

Lord, CJ, Ashworth, A, 2010: Biology-driven cancer drug development: back to the future. BMC Biol. 8:3-8

Lv, GY, Yu, F, Yao, Q, Chen, HJ, Wang, L, 2010: The role of surviving in diagnosis, prognosis and treatment of breast cancer, J. Thora. Dis. 2:100-10.

Ma, R, Mahadevappa, R, Kwok, HF, 2017: Venom-based peptide therapy: insights into anticancer mechanism. Oncotarget. 8, 59:00908-30 Mandlekar, S, Hebbar, V, Christov, K, Kong, AN, 2000: Pharmacodynamics of tamoxifen and its 4-hydroxy and N-desmethyl metabolites: activation of caspases and induction of apoptosis in rat mammary tumors and in human breast cancer cell lines. Cancer Res. 60, 23:6601-6.

Masters, JR, 2000: Animal Cell Culture: A Practical Approach. New York: Oxford University
Press.

Moriai, R, Tsuji, N, Moriai, M, Kobayashi, D, Watanbe, N, 2009: Survivin plays as a resistant factor against tamoxifen-induced apoptosis in human breast cancer cells, Breast Cancer Res. Treat. 117:261-71.

Omran, AAM, 2003: In vitro anticancer effect of scorpion Leiurus quinquestriatus and Egyptian cobra venom on human breast and prostate cancer cell lines. J. Med. Sci. 3, 1:66-86.

Ortiz, E, Possani, LD, 2018: Scorpion toxins to unravel the conundrum of ion channel structure and functioning. Toxicon150:17-27.

Osborne, CK, Boldt, DH, Clark, GM, Tent, J M, 1983: Effects of tamoxifen on human breast cancer cell cycle kinetics: accumulation of cells in early G1 phase, US National Library of Medicine NIH 43, 8:3583-5.

Rahman, A, Choudhary, IM, 2016: Anti-Angiogenesis Drug Discovery \& Development. Betham eBooks, Vol. 2. ISSN: 2210-268X (Online) Riccardi, C, Nicoletti, I, 2006: Analysis of apoptosis by propidium iodide staining and flow cytometry. Nat. Protoc. 3:1458-61.

Rondon-Lagos, M, Villegas, EV, Rangel, N, Sanchez, CM, Zaphiropoulos, GP, 2016: Tamoxifen Resistance: Emerging molecular targets. Inter.J. Mol. Sci. 17, 8:1357-62.

Shirazi, HF, Zare, A, Rabiei, H, Kobarfard, F, Ebrahim, K, et al, 2014: Anticancer Activity of Cobra Venom Polypeptide, Cytotoxin-II, against Human Breast Adenocarcinoma Cell, J. Breast Cancer, 17(4), 314-322.

Shou, J, Massarwesh, S, Osborne, CK, Wakeling, AE, Ali, S, et al, 2004: Mechanisms of tamoxifen resistance: increased estrogen receptor-HER2/neu cross-talk in ER/HER2-positive breast cancer. J. Natl. Cancer Inst. 96, 12:926-35 Snedcor, GW, Cochran, WG, 1980: Statistical methods. $7^{\text {th }}$ Ed. Ames, Lowa State University Press.

Soliman, EM, Mahdy, SE, Mosaad, WG, Hassanim, AI, El sayed, EI, 2013: Effects of different inactivatorson the efficacy of Egyptian foot and mouth disease SAT2 vaccine. J. Anim. Sci. Adv. 3, 8:391-9.

Véquaud, E, Desplanques, G, Jézéquel. P, Juin, P, Barillé-Nion, S, 2016: Survivin contributes to DNA repair by homologous recombination in breast cancer cells. Breast Cancer Res. Treat. 155, 1:53-63.

Wilson, WJ, Wakeling, EA, Morris, DI, Hickman, AJ, Dive, C, 1995: MCF-7 human mam- 
mary adenocarcinoma cell death in vitro in response to hormone-withdrawal and DNA damage. Inter. J. Cancer. 61:502-8.

Yalcin, TH, Ozen, OM, Gocmen, B, Nalbantsoy, A, 2014: Effect of Ottoman viper (Montivipera xanthina (Gray, 1849)) venom on various cancer cells and on microorganisms. Cytotechn- ology 66, 1:87-94.

Yee, D, Groos, J, 2002: How does the estrogen receptor work? Breast Cancer Res, 4, 2:62-4. Yin, L, Pan, X, Zhang, X, Guo, Y, Wang, Z, et al, 2015: Downregulation of ER- $\alpha 36$ expression sensetivites HER2 overexpressing breast cancer cells to tomxifen, Am. J. Canc. Res. 5, 2:530-44.

\section{Explanation of Figures}

Fig. 1: $\mathrm{IC}_{50}$ for $M$. xanthina \& L. quinquestriatus, venoms and Tamoxifen on $M C F-7$ cell line. (A) Venoms and Tamoxifen on $M C F-7$ cell line. (B) Leiurus venom on $M C F-7$ cell line. (C) $\mathrm{IC}_{50}$ of Montivipera venom on $M C F-7$ cell line. (D) Tamoxifen on $M C F-7$ cell line.

Fig. 2: Effects of venoms and tamoxifen on morphological alterations of MCF-7 showed induce anti-proliferative effects on treated $M C F$ 7 cell line compared to untreated one. (A) Untreated control $M C F-7$ cells, (B) Treated $M C F-7$ with $27.8 \mathrm{ug} / \mathrm{mL}$ Tamoxifen, (C)Treated $M C F-7$ with $34.4 \mathrm{ug} / \mathrm{mL}$ Montivipera venom, (D) Treated $M C F-7$ with $2.5 \mathrm{ug} / \mathrm{mL}$ Leiurus venom.

Fig. 3-4: MCF-7 Cell cycle treated with Montivipera and Leiurus venoms and tamoxifen.

Fig. 5: Apoptosis phases and necrosis of venoms and Tamoxifen on MCF-7 cell line. Apoptosis in total, early, and late and necrosis by Montivipera and Leiurus venoms and tamoxifen compared with control MCF-7 cells.

Fig. 6: Expression level of Pro and anti-apoptotic genes by R-T PCR in breast cancer cell linesMCF-7 treated with venoms and tamoxifen. Fig. 7: Control cells showed regular tumor cells (Red arrow), Cellular and nuclear pleomorphisms (Green arrow).

Fig. 8: (A) Treated MCF-7 with tamoxifen showed apoptotic bodies (yellow arrows) and remnants of necrotic cells (black arrows). (B) Tamoxifen induced a number of apoptotic bodies (yellow arrows) and colonies of necrotic cells (Red arrow).

Fig. 9: (A) MCF-7 treated with Leiurus venom showed shrunken cells with irregular nuclear and cell membranes (Red arrow), membrane blebbing (Green arrow), peripheral condensation of chromatin (Yellow arrow) and nucleolar segregation (Black arrow). (B) Treated cells with Leiurus detected swollen necrotic cells (Green arrows) with irregular cell membrane, necrotic cell debris (yellow arrows) and apoptotic bodies (Red arrows). (C) Treated cells showed shrunken with irregular nuclear and cell membranes (Red arrow), membrane blebbing (Green arrow), peripheral condensation of chromatin (Yellow arrow) and nucleolar segregation (Black arrow). (D) Montivipera venom on MCF-7 induced small cells with irregular membranes (Red arrows), membrane blebbing (Black arrow) and apoptotic bodies (Green arrows). (E) Leiurus venom with $M C F-7$ cell lines showed small cells with irregular nuclear and cell membranes (Yellow arrow), apoptotic bodies (Red arrow), and necrotic swollen cell mixed with euchromatin and heterochromatin (Black arrow).

Fig. 10: (A) MCF-7 cells treated with Leiurus venom showed shrunken apoptotic cells (red arrows). (B) MCF-7 cells with Montivipera venom showed small shrunken apoptotic cells with irregular cellular and nuclear membranes (Yellow arrows), peripheral condensation of chromatin (red arrows) as well as nucleolar segregation. (c) Montivipera venom on MCF-7 cell lines; shrunken apoptotic cells with irregular cellular, nuclear membranes (red arrows) and membrane blebbing (Yellow arrow) and apoptotic bodies (black arrow).

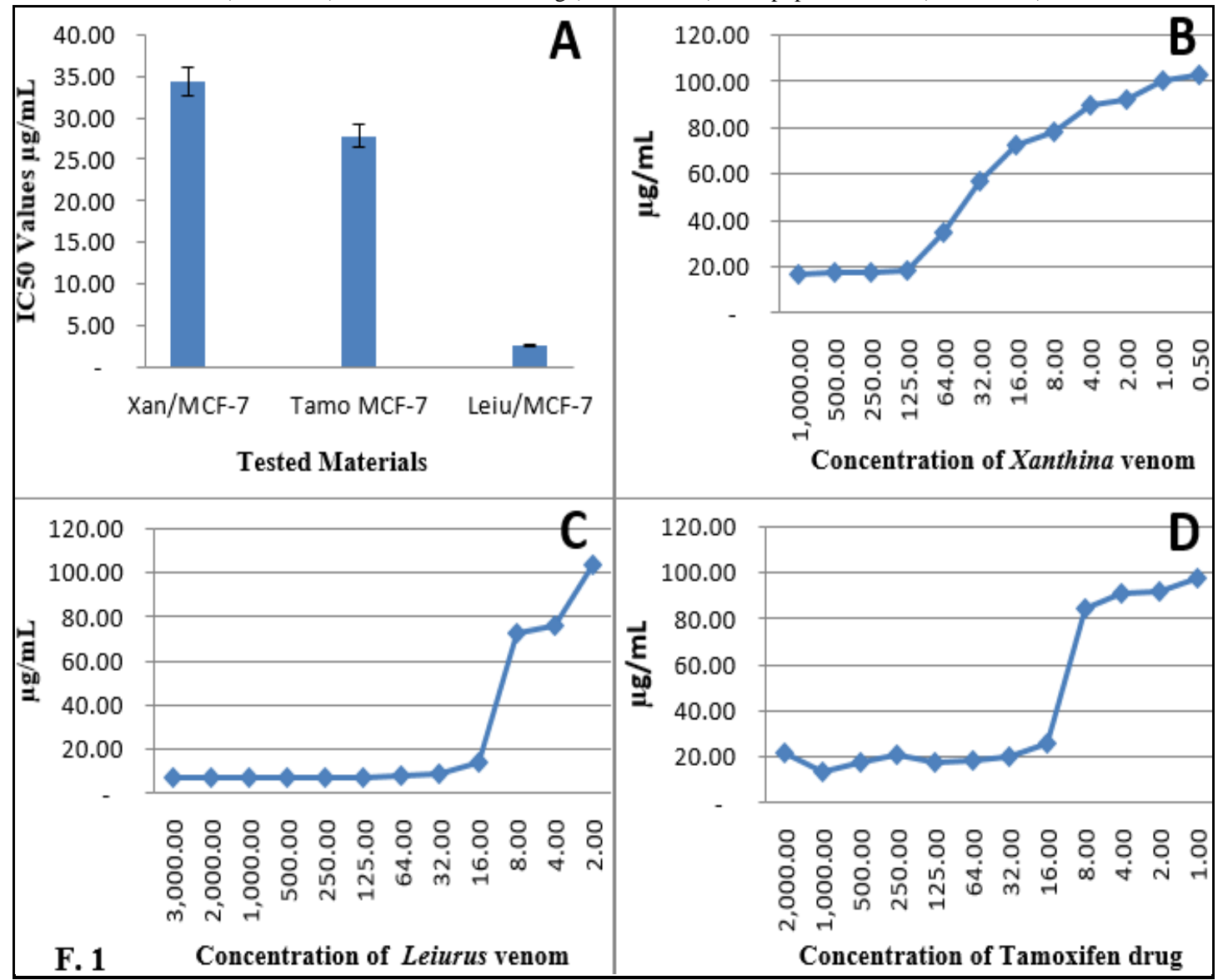




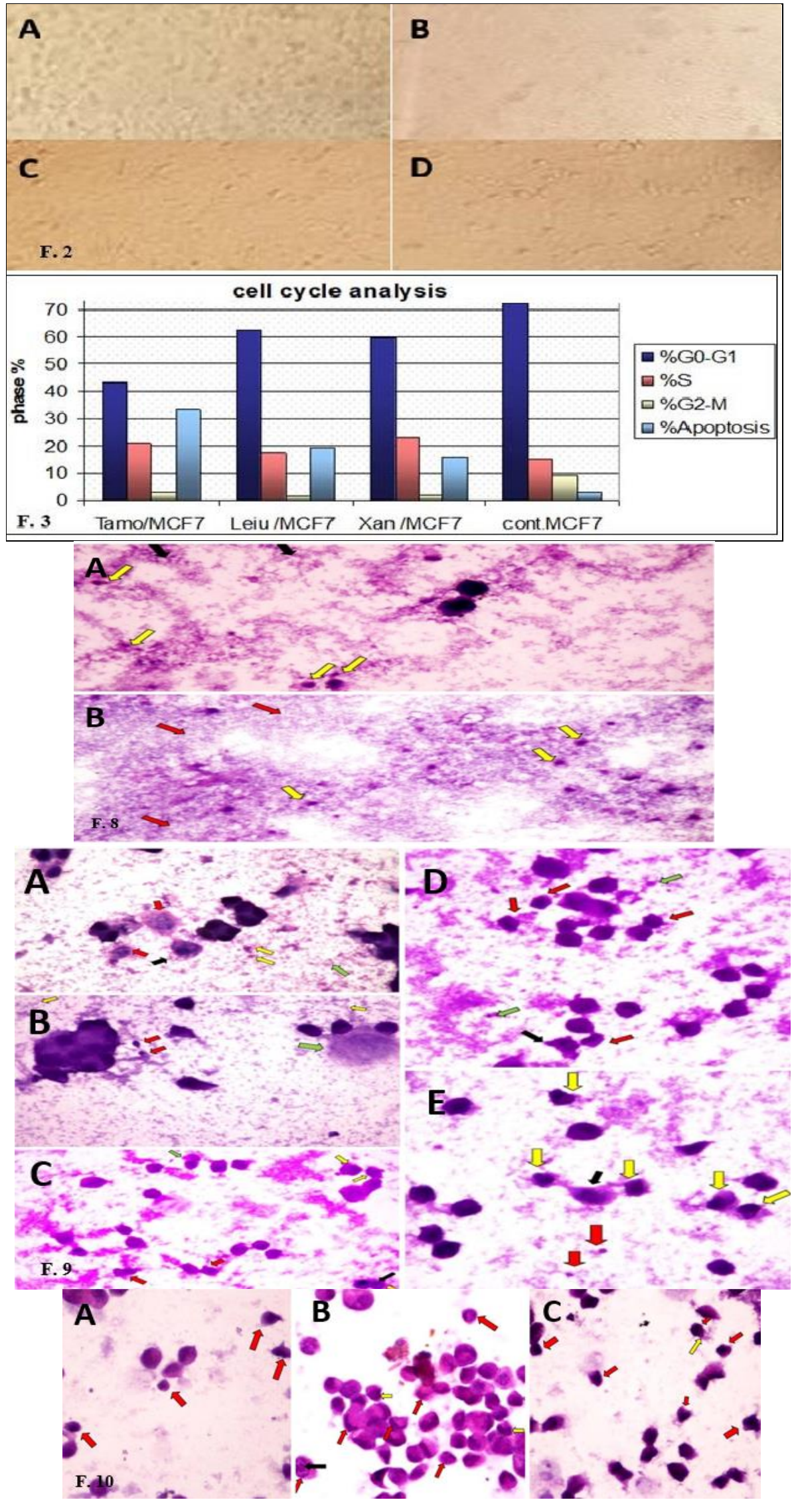

